\title{
FORMACIÓN DE ELEMENTOS ANATÓMICOS EN MADERAS DURAS: UNA REVISIÓN DESDE UNA PERSPECTIVA GENÓMICA
}

\author{
ANATOMICAL ELEMENTS FORMATION IN HARDWOODS: A REVIEW \\ FROM A GENOMIC PERSPECTIVE
}

\author{
Isabel Carrillo ${ }^{1,2}$, Juan Pedro Elissetche ${ }^{3}$, Sofía Valenzuela ${ }^{1,2}$, Regis Teixeira Mendonça ${ }^{1,2, \star}$
}

\begin{abstract}
RESUMEN
La madera es un recurso natural renovable que proporciona materia prima para la construcción, generación de energía, fibras para la producción de pulpa y papel, paneles y tableros, y más recientemente para biocombustibles y biomateriales, lo que la hace el quinto producto comercial más importante del mundo. Diferencias en las propiedades físicas, químicas y anatómicas de la madera la hacen un material altamente variable y complejo. Estas propiedades influyen de forma directa en su valor comercial y derivan del tamaño, forma y arreglo de los diferentes tipos de células, y de la estructura y composición química de la pared celular de las distintas células del xilema. Éstas a su vez, están controladas por distintos factores ambientales y genéticos que regulan los procesos de biosíntesis de los diferentes componentes de la madera. Para aplicar herramientas moleculares y genéticas que permitan optimizar los procesos de selección de especies forestales con características superiores, es necesario entender los mecanismos que regulan estas propiedades, lo cual incluye comprender la dinámica de la estructura de la pared celular desde la formación de la célula cambial inicial hasta la formación de las células diferenciadas finales que conforman el xilema. La presente revisión explora las principales características anatómicas y el proceso de xilogénesis, enfocado particularmente en angiospermas, discutiendo los aspectos genéticos involucrados en la determinación de las características anatómicas de la madera, como dimensiones de los elementos celulares y características de la fibra, basándose en diferentes estudios realizados con especies de los géneros Populus y Eucalyptus, además de la planta modelo Arabidopsis thaliana.
\end{abstract}

Palabras clave: Maderas duras, xilogénesis, expansión celular, pared celular secundaria, expresión genética.

\begin{abstract}
Wood is a renewable natural resource that provides raw material for construction, power generation, fibers for pulp and paper production, panels and boards, and more recently, biofuels and biomaterials, making it the fifth most important commercial product in the world. The wood is a highly variable and complex material that has different chemical, physical and anatomical properties that are influencing their commercial value. These properties depend on the size, shape and arrangement of the different cell types, and of the structure and chemical composition of the xylem cell wall. At the same time, these properties are controlled by different environmental and genetic factors that regulate the biosynthesis processes of the different wood components. To apply molecular and genetic tools to optimize the selection processes of forest species with superior traits, it is necessary to understand the mechanisms that regulate these properties, as the dynamics of cell wall structure from the initial cambial cell formation to the final differentiated cells formation that compose the xylem. This review explores the
\end{abstract}

${ }^{1}$ Centro de Biotecnología, Universidad de Concepción, Concepción, Chile.

${ }^{2}$ Facultad de Ciencias Forestales, Universidad de Concepción, Concepción, Chile.

${ }^{3}$ Genómica Forestal S.A., Universidad de Concepción, Concepción, Chile.

Corresponding author: "rteixeira@udec.cl

Recibido: 21.06.2012 Aceptado: 21.09.2012 
main anatomical traits and the xylogenesis processes, particularly focused in angiosperms, discussing the genetic aspects involved in the determination of wood anatomical characteristics, as cellular elements and fiber characteristics, based on different studies with species of the Populus and Eucalyptus genus, besides the model plant Arabidopsis thaliana.

Keywords: Hardwoods, xylogenesis, cell expansion, secondary cell wall, gene expression.

\section{INTRODUCCIÓN}

Las especies de maderas duras (angiospermas) tienen una anatomía más compleja y una mayor variedad de células que las maderas blandas (gimnospermas). En maderas duras, los roles de conducción y soporte son llevados a cabo por diferentes células (vasos y fibras) y, además del parénquima radial, también está presente el parénquima longitudinal. Las células parenquimáticas están principalmente involucradas con el almacenamiento de sustancias de reserva (Thomas 1977, Ek et al. 2009). Las fibras en maderas duras forman, junto a los elementos de vasos, el tejido básico del xilema, y su función principal es dar soporte mecánico al árbol, aunque en algunas especies también participan en el transporte de agua. Las fibras de maderas duras son más pequeñas que las traqueidas de maderas blandas, tienen paredes celulares de mayor grosor y lúmenes más pequeños (Karlsson 2006).

Los vasos se componen por células individuales, llamadas elementos de los vasos, donde las paredes que conectan a los elementos del vaso están perforadas para permitir la formación de un tubo adaptado para conducir agua a través del árbol. Los vasos depositan una pared secundaria engrosada, pero más delgada en comparación a las de las fibras (Ek et al. 2009). Además, presentan punteaduras, que no tienen pared secundaria, para permitir la comunicación, transporte de agua y nutrientes con los vasos y/o células del parénquima adyacentes (Déjardin et al. 2010).

Una de las principales características que determina la calidad de la madera es la densidad, la cual está principalmente determinada por la proporción de fibra y otros elementos celulares presentes en el xilema. En las maderas de baja densidad, los vasos ocupan una mayor proporción, y en maderas más densas, las fibras de paredes más gruesas ocupan una mayor proporción del volumen de madera (Butterfield 2006).

Existe un gran número de estudios en plantas donde se han identificado muchos de los genes implicados en las diferentes etapas de la xilogénesis, sin embargo, en su mayoría están orientados a relacionar la expresión y función de esos genes a las características químicas que presenta la madera, como contenido de celulosa, lignina y hemicelulosa, y sus procesos de biosíntesis (Hertzberg et al. 2001, Li et al. 2006, Somerville et al. 2006), pero son muy pocos los estudios que los relacionen a las características anatómicas de la madera. Los genes que participan en la reestructuración y en el control de la deposición de celulosa de la pared celular secundaria podrían estar involucrados con la formación de los elementos anatómicos de la madera, determinando la calidad, rendimiento y valor comercial de esta.

\section{XILOGÉNESIS O PROCESO DE FORMACIÓN DE LA MADERA}

La xilogénesis comienza en el cambium vascular, responsable del crecimiento secundario, que produce xilema y floema hacia el interior y exterior del tronco, respectivamente. El cambium vascular está formado por dos tipos de células, las células iniciales fusiformes, que mediante divisiones periclinales (paralelas al eje longitudinal) dan origen al sistema celular axial; y las células iniciales radiales, que mediante divisiones anticlinales (perpendiculares al eje longitudinal) dan origen al sistema celular radial (Mellerowicz et al. 2001). El crecimiento y desarrollo celular involucra una combinación de crecimiento simplástico (cuando todas las células vecinas crecen juntas) e intrusivo (cuando una célula crece por sobre las demás) que involucran una modificación de las pectinas, hemicelulosas y celulosa (Gray-Mitsumune et al. 2008, Mellerowicz y Sundberg 2008, Siedlecka et al. 2008). Al inicio de la 
diferenciación, las células jóvenes del xilema se alargan sin aumentar su ancho, en esa etapa tienen una pared celular primaria delgada, después aumentan su diámetro, establecen su pared celular secundaria y adquieren las características distintivas de su tipo de célula, como elementos del vaso, fibras o parénquima (Déjardin et al. 2010).

La expansión axial de los vasos está limitada, a diferencia de las fibras que se elongan considerablemente en dirección axial mientras mantienen una expansión radial moderada. La elongación de las fibras ocurre a través de un crecimiento intrusivo en punta y requiere de una biogénesis local de la pared y disolución de la lamela media de las células vecinas. Cuando las fibras alcanzan su tamaño final, depositan una pared secundaria más gruesa (Mellerowicz et al. 2001, Déjardin et al. 2010). La formación de la pared secundaria en todas las células del xilema ocurre cuando la expansión radial se ha completado, ésta deposición está marcada por la formación de una matriz densa de microfibrillas de celulosa, dispuestas de forma transversal, que limitan la expansión radial. La primera capa que se forma es la S1, que tiene un ángulo de microfibrillas casi transversal que cambia gradualmente a la disposición longitudinal que caracteriza a la capa más gruesa, la capa S2. Finalmente, se forma la capa S3, que se origina después de una abrupta reorientación de las microfibrillas que vuelven a una orientación transversal. Los cambios en la orientación de las microfibrillas durante la formación de las sucesivas capas de la pared celular son siempre paralelos a la reorientación de los microtúbulos corticales (Mellerowicz et al. 2001). En algunas angiospermas, como Populus, se ha visto que la formación de la pared secundaria comienza en los elementos de los vasos y en las células que los rodean. Los elementos de los vasos tienen 3 capas de pared secundaria similares a las de las fibras, pero la capa S2 es proporcionalmente más delgada, de acuerdo a su longitud (Mellerowicz et al. 2001). Cuando los vasos y las fibras ya han depositado la pared celular secundaria, estos se lignificarán. Al comenzar la deposición de lignina, esta se asocia gradualmente a la hemicelulosa presente en la pared celular, eliminando agua y formando una célula rígida e impermeable (Déjardin et al. 2010). La lignificación comienza en los elementos de los vasos y las células que los rodean que tienen pared secundaria, mientras las fibras y las células aisladas se lignifican después. La lignina se detecta primero en la lamela media, particularmente en las esquinas de las células, cuando las células han completado la deposición de la capa S1. Posteriormente, avanza hacia el interior durante la formación de la capa S2. La deposición de lignina es más intensa cuando la capa S3 se forma, donde finalmente avanza hacia el lumen celular hasta que todas las capas de la pared son lignificadas (Mellerowicz et al. 2001). Finalmente, cuando la lignificación se ha completado, la célula se somete a muerte celular programada, donde la membrana de la vacuola se disocia y libera hidrolasas específicas, el $\mathrm{pH}$ citosólico baja activando hidrolasas citosólicas que hacen desaparecer los organelos y el núcleo. Las células del parénquima pueden permanecer vivas y funcionales por mucho tiempo aunque se hayan lignificado, sin embargo, posteriormente también morirán y pasarán a formar parte del duramen del árbol (Déjardin et al. 2010).

\section{Expansión Celular}

Como se mencionó anteriormente, el crecimiento celular involucra una combinación de crecimiento simplástico e intrusivo que pueden estar controlados por una serie de mecanismos complejos regulados por diversos factores genéticos. En la zona de expansión y crecimiento de las células que forman el xilema, participan una serie de proteínas y enzimas que permiten el aflojamiento de la tensión de la pared celular, dando paso a su reestructuración y posterior expansión celular, ya que se ha visto que el cambium vascular y zonas adyacentes son sitios de alta expresión de genes que codifican enzimas que modifican la pared celular, como expansinas, celulasas, endo-transglicolasas, pectin metil esterasas, poligalacturonasas y pectin/pectato liasas (Darley et al. 2001, Mellerowicz y Sundberg 2008).

\section{Expansinas}

Las expansinas (exp) forman una gran familia de multigenes en las plantas, que se dividen en $\alpha-\mathrm{y}$ $\beta$-expansinas (Sampedro y Cosgrove 2005). Los transcritos de Pttexpal (expa, una $\alpha$-expansina) son detectados en mayor cantidad en el cambium secundario de Populus a través de ensayos con bibliotecas de secuencias expresadas en diferentes tejidos de esta especie (Gray-Mitsumune et al. 2004). Por lo 
tanto, es probable que dentro de esta gran familia de genes, sea específicamente éste el grupo de genes involucrado en el proceso formación de madera. Estas enzimas son consideradas los agentes primarios del crecimiento ácido de la pared celular (Rayle y Cleland 1992), afectando su plasticidad mediante el rompimiento de enlaces covalentes entre las microfibrillas de celulosa y xiloglucanos (Cosgrove 2000, Sampedro y Cosgrove 2005). El pH de la pared celular es determinado por la actividad de la enzima $\mathrm{H}^{+}$ ATPasa (adenosin-trifosfatasa) presente en la membrana plasmática, la cual bombea protones hacia la pared celular. La pared celular típicamente tiene un $\mathrm{pH}$ de 5,5. Sin embargo, bajo ciertas circunstancias, como respuesta a hormonas de crecimiento, estímulos externos como la luz y procesos morfogénicos, el pH puede ser inferior a 4,5. En estas condiciones las expansinas estarían activamente participando en el ablandamiento de la pared celular vegetal. Su acción puede afectar la composición y estructura de la pared celular, regulando el acceso de enzimas que degradan componentes específicos en ella, por lo cual podrían estar relacionadas con el crecimiento simplástico e intrusivo de elongación de las fibras y vasos en la madera (Sampedro y Cosgrove 2005). A través de la generación de líneas transgénicas, Gray-Mitsumune et al. (2008) analizaron el efecto de la sobreexpresión del gen expa en Populus, observando un aumento significativo en el diámetro de las fibras y en la longitud de los elementos de los vasos, pero no en el diámetro de los elementos de los vasos, lo cual indicaría que EXPA tiene una función sobre el crecimiento simplástico de las fibras y no en el crecimiento lateral intrusivo de los vasos. Los elementos de los vasos son lignificados primero que las fibras, por lo tanto, esto haría que no respondan a la acción de EXPA de forma más temprana, al contrario de las fibras (Mellerowicz et al. 2001, Gray-Mitsumune et al. 2008).

Diferentes estudios relacionan el efecto de las expansinas sobre el crecimiento intrusivo apical de las fibras (Im et al. 2000, Darley et al. 2001, Cosgrove et al. 2005), sin embargo los resultados obtenidos por Gray-Mitsumune et al. (2008) no demostraron un efecto significativo de la sobreexpresión de expa en este tipo de células en Populus. Es posible que la acción de EXPA en el crecimiento intrusivo apical requiera de una señal para que el transcrito de expa se transporte a su sitio de acción, las puntas de las fibras; esto debido a que se ha observado que los transcritos de expa se localizan en los extremos apicales de éstas células (Im et al. 2000, Gray-Mitsumune et al. 2004). Por otro lado, el crecimiento intrusivo requiere de la disolución de la lamela media para que las células en crecimiento la puedan penetrar; respecto a ello, se ha observado que la pectin metilesterificación del homogalacturano, principal pectina presente en la lamela media de angiospermas, promueve la elongación de las fibras. Por lo tanto, probablemente la estrategia para aumentar la longitud de éstas células deba considerar el efecto de otros genes (GrayMitsumune et al. 2008, Siedlecka et al. 2008).

\section{Xiloglucano endotransglicosilasas/hidrolasas}

El xiloglucano es una hemicelulosa importante de la pared celular primaria que se une covalentemente a la celulosa, revistiendo y uniéndose a las microfibrillas de celulosa adyacentes, formando la red de sostén de la pared (Nishikubo et al. 2011). La remodelación de esta red por parte de las expansinas, celulasas, xiloglucanasas y xiloglucano transglicolasas, se cree juega un rol mayor en la regulación del ablandamiento de la pared, lo cual lleva al crecimiento celular (Sampedro y Cosgrove 2005). Xiloglucano endotransglicosilasas/hidrolasas (XTH) es una familia que comprende dos tipos de enzimas, la xiloglucano endotransglicolasa (XET) y la xiloglucano endohidrolasa (XEH). La actividad de XEH genera el rompimiento de los enlaces $\beta-(1,4)$ glicosídicos en las moléculas de xiloglucano, mientras que XET ensambla nuevamente las cadenas de xiloglucano transfiriendo el segmento xiloglucanil al O-4 del extremo no reducido de un aceptor xiloglucano (Fry 1992, Nishikubo et al. 2011). La familia de genes $x$ th está sujeta a regulación tejido-específica, ambiental y hormonal, y su rol en el crecimiento y desarrollo celular aún no está claro; sin embargo, se ha visto que diferentes isoformas de XTH inducen la dureza o ablandamiento en la pared celular (Fry et al. 1992, Xu et al. 1996, Vissenberg et al. 2000, Nishikubo et al. 2011). La expresión de genes $x$ th es alta en las regiones donde la formación de la pared es activa, en zonas de elongación y en regiones donde la deposición de la pared continúa después de la elongación celular (Bourquin et al. 2002, Sampedro y Crosgrove 2005, Nishikubo et al. 2011). Nishikubo et al. (2011) sobreexpresaron una isoforma de la enzima XTH en Populus, obteniendo como resultado un 
aumento en la expansión de los elementos de los vasos, pero el diámetro de fibras y la longitud de ambos elementos celulares no se vieron afectados significativamente. Respecto a los resultados observados por estos autores, se argumenta como alternativa que el efecto de XTH en la expansión celular dependa de las cantidades de XTH y del xiloglucano secretado a la pared celular. El xiloglucano entrante, que forma un pool de sitios de unión y corte, y el xiloglucano que ya está "atado" a las microfibrillas de celulosa en la pared, compiten por XTH. Por esa razón, cuando el xiloglucano entrante es abundante, las XTH entrantes pueden romperlo e incorporarse a la pared celular como complejos covalentes XTHxiloglucano; esas uniones covalentes de XTH pueden transglicosilar extremos no reducidos disponibles del xiloglucano unido a la pared (Sulová et al. 1998), fortaleciendo la red de xiloglucano en la pared celular. Sin embargo, si se sintetiza más XTH que xiloglucano, el excedente de XTH puede entrar libre a la pared y romper las cadenas de xiloglucano unidas a las microfibrillas, dando lugar a una relajación de la tensión, permitiendo el ablandamiento de la pared y favoreciendo la expansión celular (Darley et al. 2001). Por lo tanto, el efecto de XTH en la expansión celular puede depender de los grados de biosíntesis de xiloglucano y secreción a la pared celular, y de la cantidad de XTH, lo cual puede diferir entre los distintos tipos de células, siendo menor en los elementos de los vasos y mayor en las fibras (Nishikubo et al. 2011).

\section{Pectin metil esterasas}

El crecimiento y elongación de las fibras debe penetrar la lamela media, por lo que se requiere de su disolución a través de modificaciones de las moléculas de pectinas que la conforman (Goulao et al. 2011). La lamela media provee una superficie de contacto entre células vecinas y la adhesión entre células, la cual depende de la formación de enlaces intermoleculares entre las moléculas de pectina, donde esos enlaces intermoleculares tienen influencias en la plasticidad de la pared celular. El principal componente péctico que conforma la lamela media es el homogalacturonano (HGA), un homopolímero lineal de ácido galacturónico que puede ser metilesterificado en el carbono 6, o llevar grupos acetilos en los carbonos 2 y 3 (Pelleoux et al. 2007).

El HGA puede ser de-metilesterificado por las pectin metil esterasas (PME) presentes en la pared celular, liberando metanol y protones, creando grupos carboxilos negativamente cargados (Knox et al. 1990, Pelleoux et al. 2007). Esos residuos carboxílicos libres pueden interaccionar con diferentes moléculas, dando lugar a la formación de diferentes estructuras en la lamela media. Un tipo de enlace intermolecular ocurre cuando los iones de calcio $\left(\mathrm{Ca}^{+2}\right)$ interactúan con la forma acídica de las moléculas de HGA, formando estructuras rígidas llamadas "caja de huevos" (Taiz y Zeiger 2003, Pelleoux et al. 2007, Siedlecka et al. 2008). En este proceso se ha visto que participan activamente enzimas PME, donde se ha demostrado que una mayor expresión del gen que codifica esta enzima, tiene un efecto negativo en el crecimiento simplástico e intrusivo de las células, limitando su crecimiento. Siedlecka et al. (2008) emplearon Populus transgénico sobreexpresando y silenciando esta enzima, donde observaron que la sobreexpresión de pmel disminuía las dimensiones de vasos y fibras, mientras que con su silenciamiento ocurría lo contrario. El silenciamiento de pmel estimula la expansión radial de los elementos de los vasos y fibras, indicando que PME1 es un regulador negativo de la plasticidad de la pared en células del xilema en desarrollo, ya que a medida que aumentan los niveles de PME1, disminuye el largo de fibras y diámetro de las células del xilema.

El crecimiento intrusivo apical de las fibras requiere la disolución de la lamela media, la fluencia de la pared celular entre células adyacentes para crear espacio para el crecimiento en punta, y la biogénesis local de la pared celular en la punta de la fibra (Mellerowicz et al. 2001, Déjardin et al. 2010). Posiblemente PME1, e isoformas similares, están involucradas en todos estos procesos; sin embargo, se propone que su gran impacto es a través de la modificación de la lamela media, mediante la generación de tramos de HGA de-metilesterificados, creando estructuras rígidas pectina-calcio-pectina, estabilizando la red de pectina en la lamela media, impidiendo la penetración de fibras y otros elementos celulares en crecimiento (Siedlecka et al. 2008). Por otro lado, la presencia de HGA de-esterificado parece ser esencial para la lignificación del xilema, ya que la estructura caja de huevo formada por $\mathrm{Ca}^{2+}$ y $\mathrm{HGA}$ se conoce por unirse 
a una clase de peroxidasas que posiblemente inician la polimerización de la lignina; además el grado de HGA de-metilesterificado es un sustrato que afecta interacciones enzimáticas específicas, alterando la estructura y composición de la pared celular (Pelleoux et al. 2007).

\section{FORMACIÓN DE LA PARED SECUNDARIA}

Posterior a la expansión celular, ocurre la formación de la pared secundaria, donde el complejo enzimático celulosa sintasa (CesA) comenzará a depositar las microfibrillas de celulosa (Somerville et al. 2006). Las principales proteínas involucradas en este proceso son:

\section{Tubulinas}

Se cree que los microtúbulos, heterodímeros formados por $\alpha$-tubulina (TUA) y $\beta$-tubulina (TUB), están involucrados en el alineamiento de las microfibrillas durante la deposición de la pared celular secundaria, sirviendo activamente como rieles moleculares que guían los complejos enzimáticos (rosetas de CesA) que las sintetizan o, pasivamente, formando canales que limitan el movimiento lateral de las rosetas de CesA (Paredez et al. 2006, Somerville et al. 2006). Esto debido a que se ha observado que en varios sistemas biológicos los microtúbulos corticales del citoplasma están orientados de forma paralela a las microfibrillas de celulosa en la pared celular (Gunning y Steer 1996, Baskin 2001).

La formación del microtúbulo comienza con la creación de un ensamblaje competente del heterodímero $\alpha / \beta$, donde la asociación de las subunidades $\alpha$ y $\beta$ es asistida por co-factores que dirigen su unión. Ese ensamblaje competente puede ser incorporado al arreglo del microtúbulo, los cuales son constantemente re-arreglados entre la fase de crecimiento o contracción para facilitar la estabilización o desestabilización de proteínas. Ese comportamiento es influenciado por factores temporales y espaciales que afectan la concentración de TUA y TUB dentro del citoplasma (Spokevicius et al. 2007).

Oakley et al. (2007) analizaron los patrones de expresión de los transcritos de tua y tub en diferentes tejidos de Populus a través de qRT-PCR, utilizando primers específicos para ocho genes tua y 20 genes tub. Ellos observaron que en el xilema de Populus, tres genes tua se expresaron en comparación al gran número de genes tub detectado, sin embargo, los niveles de expresión de los genes tua fueron mayores. Por lo tanto, sugieren que la pequeña familia de genes tua exhibe una funcionalidad más amplia, regulando la formación de madera y el desarrollo del polen, mientras que la gran familia de genes tub exhibe una funcionalidad especializada en el desarrollo del xilema.

Otros estudios evidencian que las isoformas de TUA y TUB predominantes en el xilema están asociadas a la síntesis de celulosa durante la formación de la pared celular secundaria, probablemente influyendo en el control que ejercen los microtúbulos sobre el complejo enzimático de CesA (Bhandari et al. 2006, Oakley et al. 2007, Spokevicius et al. 2007). El primero se refiere a la inmunolocalización de las proteínas de TUA y TUB encontradas en las fibras de xilema y floema que depositan su pared celular secundaria. El segundo se refiere al aumento de expresión de diferentes genes tua y tub en madera de tensión. Sin embargo, a través de la transformación genética también surge un reporte que relaciona el nivel de transcrito de tubulina con el ángulo microfibrilar (MFA). Spokevicius et al. (2007) demuestra que el silenciamiento de $t u b 1$ en E. grandis, tiene un efecto sobre el MFA de la pared secundaria, el cuál disminuyó significativamente en los sectores del xilema donde se indujo el silenciamiento, en comparación a los sectores no transformados. Sin embargo, el mecanismo mediante el cual los microtúbulos influencian el depósito de las microfibrillas de celulosa en la capa S2 de la pared celular secundaria de las fibras aún se desconoce, pero probablemente esto involucre diferentes factores, incluyendo la variedad de proteínas asociadas a los microtúbulos (Zhong et al. 2002). 


\section{Fasciclin tipo arabinogalactanos}

Las proteínas arabinogalactano (AGPs) son una clase de glicoproteínas, ricas en hidroxiprolina que están altamente glicosiladas. Cuando estas proteínas poseen el dominio fasciclin, se denominan fasciclin tipo arabinogalactano (FLA) (Gaspar et al. 2001; Johnson et al. 2003). Las AGPs son proteínas ampliamente distribuidas en el reino vegetal y se encuentran principalmente en las paredes celulares, membrana plasmática y en los espacios intracelulares; están implicadas en diversos roles como la diferenciación, el reconocimiento célula-célula, embriogénesis somática y muerte celular programada (Lafarguette et al. 2004). De la misma forma, para el dominio fasciclin se ha visto que varias proteínas presentes en la matriz extracelular de la célula con estos dominios muestran una función importante en el desarrollo y adhesión de moléculas (Gaspar et al. 2001, Johnson et al. 2003). Sin embargo, no existe evidencia experimental que permita dilucidar la función biológica de este tipo de proteínas (Lafarguette et al. 2004, MacMillan et al. 2010).

Lafarguette et al. (2004) analizaron los niveles de expresión de genes homólogos codificantes para FLA en cambium y xilema de madera de tensión y opuesta de Populus, pero ninguno de los transcritos de $f l a$ fueron detectados en las muestras de la zona cambial. Considerando que el cambium al ser recolectado no solo contiene células del cambium, sino que también células jóvenes de xilema y floema en expansión, se sugiere que fla se expresa principalmente durante la diferenciación del xilema, una vez que las células xilemáticas han comenzado a depositar la pared celular secundaria (Lafarguette et al. 2004). Ellos observaron una expresión diferencial de 10 genes $f l a$, de un total de 15 , las que presentaban una alta señal en el xilema en desarrollo y maduro de madera de tensión, en comparación a la nula señal observada en el xilema en desarrollo y maduro de madera opuesta. Esto sugiere una importante, pero aún indeterminada función de estas proteínas durante la xilogénesis y formación de la pared celular secundaria. Considerando las características de la madera de tensión y opuesta, es posible que la función de FLA esté relacionada con el establecimiento de conexiones entre la pared celular y el citoesqueleto durante la expansión y elongación de las fibras (Lafarguette et al. 2004). De forma similar, Qiu et al. (2008) realizaron diferentes análisis en el xilema de las ramas superiores e inferiores, y el xilema vertical de E. grandis. A partir de una biblioteca EST de $E$. grandis realizaron análisis de expresión mediante microarreglos, donde detectaron que los genes Egrfla1 y Egrfla2 estaban sobreexpresados en el xilema superior de las ramas, al contrario del xilema inferior, donde la expresión era baja. Análisis de "northern blot" demuestran la mayor expresión de los genes Egrfla1 y Egrfla2 en el xilema superior de las ramas, donde el MFA era menor. La expresión de Egrfla1 y Egrfla2 está fuertemente relacionada a los cambios en la orientación de las microfibrillas, donde las evaluaciones del MFA en las ramas de E. grandis indican ángulos que oscilan en $\operatorname{los} 10^{\circ}$ en las fibras del xilema superior, y $50^{\circ}$ en las fibras del xilema inferior. Diferencias similares se han encontrado en las ramas de E. globulus, con MFA de $13^{\circ}$ en las fibras del xilema superior, y $40^{\circ}$ en las fibras del xilema inferior (Washusen et al. 2005); y en E. nitens, con MFA de $19^{\circ}$ y $45^{\circ}$ en xilema superior e inferior de ramas, respectivamente (Qiu et al. 2008), donde también se ha observado expresión diferencial de genes $f l a$ en los tejidos xilemáticos superiores e inferiores de las ramas (MacMillan et al. 2010). Por lo tanto, se sugiere que este tipo de AGP también está contribuyendo a la orientación de las microfibrillas de celulosa dentro de la pared secundaria, considerando que se ha demostrado en Arabidopsis que ortólogos del gen fla son altamente expresados en el xilema, y además son co-regulados con los genes CesA específicos de la pared celular secundaria (Qiu et al. 2008).

A través de la generación de líneas transgénicas no se ha obtenido un fenotipo claro que permita entender la función biológica de estas proteínas. Sin embargo, parece ser que uno de sus principales efectos sobre el xilema es influenciar su biomecánica. MacMillan et al. (2010) generaron líneas mutantes de Arabidopsis, silenciando los genes Atfla11 y Atfla12. La morfología observada en los mutantes fue similar al control no transformado, y a nivel celular, la forma y tamaño de las células tampoco mostró diferencias con su contraparte no transformada, y tampoco el grosor de las paredes celulares. Sin embargo, cuando se analizó la biomecánica de las plantas, como la fuerza de tensión y modulo de elasticidad del xilema, se observaron diferencias significativas en las líneas transformadas, lo cual mostró relación 
con el MFA evaluado en las fibras del xilema. Por lo tanto, es posible que FLA pueda afectar el MFA funcionando con un rol de señalización que permita la interacción de las microfibrillas de celulosa en formación con los microtúbulos intracelulares, siendo los oligosacaridos de arabinosa presentes en FLA los responsables de actuar como moléculas de señalización (MacMillan et al. 2010).

La tabla 1 muestra un resumen con los principales genes estudiados y su efecto en el proceso de formación de elementos anatómicos y pared celular de maderas duras.

Tabla 1. Genes involucrados en la determinación de características anatómicas.

\begin{tabular}{|c|c|c|c|c|c|}
\hline Proteínas & Especie & Genes & Método & Observaciones & Referencia \\
\hline EXP & $\begin{array}{l}\text { P. tremula } \mathrm{x} \\
\text { P. tremuloides }\end{array}$ & Pttexpal & $\begin{array}{c}\text { Transformación } \\
\text { genética } \\
\text { (Sobreexpresión } \\
\text { mediante promotor 35S } \\
\text { CaMV) }\end{array}$ & $\begin{array}{l}\text { Aumento del diámetro de } \\
\text { fibra y longitud de elementos } \\
\text { del vaso. }\end{array}$ & $\begin{array}{l}\text { Gray- } \\
\text { Mitsumune } \\
\text { et al. } 2008\end{array}$ \\
\hline XTH & $\begin{array}{l}\text { P. tremula } \mathrm{x} \\
\text { P. tremuloides }\end{array}$ & $\begin{array}{l}\text { Ptxtxet 16- } \\
\quad 34\end{array}$ & $\begin{array}{c}\text { Transformación } \\
\text { genética } \\
\text { (Sobreexpresión } \\
\text { mediante promotor 35S } \\
\text { CaMV) }\end{array}$ & $\begin{array}{l}\text { Aumento en la expansión de } \\
\text { elementos del vaso. }\end{array}$ & $\begin{array}{l}\text { Nishikubo et } \\
\text { al. } 2011\end{array}$ \\
\hline PME & $\begin{array}{l}\text { P. tremula } \mathrm{x} \\
\text { P. tremuloides }\end{array}$ & Pttpmel & $\begin{array}{c}\text { Transformación } \\
\text { genética } \\
\text { (Sobreexpresión } \\
\text { mediante promotor } 35 \mathrm{~S} \\
\text { CaMV y silenciamiento } \\
\text { con técnica antisentido) }\end{array}$ & $\begin{array}{l}\text { Sobreexpresión: Disminución } \\
\text { longitud y diámetro de fibras. } \\
\text { Silenciamiento: Aumento } \\
\text { longitud de fibras y aumento } \\
\text { de diámetro de fibras y vasos. }\end{array}$ & $\begin{array}{l}\text { Siedlecka et } \\
\text { al. } 2008\end{array}$ \\
\hline \multirow{3}{*}{ TUB } & E. grandis & Egrtubl & $\begin{array}{c}\text { Transformación } \\
\text { genética } \\
\text { (Transformación in } \\
\text { vivo) }\end{array}$ & Alteración en el MFA. & $\begin{array}{l}\text { Spokevicius } \\
\text { et al. } 2007\end{array}$ \\
\hline & E. grandis & Egrtubl & $\begin{array}{l}\text { Análisis de expresión } \\
\text { (Northern blot) }\end{array}$ & $\begin{array}{c}\text { Mayor expresión en xilema } \\
\text { superior de ramas, respecto a } \\
\text { xilema inferior. }\end{array}$ & $\begin{array}{l}\text { Spokevicius } \\
\text { et al. } 2007\end{array}$ \\
\hline & P. tremuloides & $\begin{array}{l}\text { Poptrtual- } \\
8 \mathrm{y} \\
\text { Poptrtubl- } \\
20\end{array}$ & $\begin{array}{l}\text { Análisis de expresión } \\
\text { (PCR en tiempo real) }\end{array}$ & $\begin{array}{c}\text { Mayor expresión de } \\
\text { isoformas TUA y TUB en } \\
\text { madera de tensión, respecto } \\
\text { al xilema vertical. }\end{array}$ & $\begin{array}{l}\text { Oakley et al. } \\
\quad 2007\end{array}$ \\
\hline \multirow{4}{*}{ FLA } & $\begin{array}{l}\text { P. tremula } \mathrm{x} \\
\quad \text { P. alba }\end{array}$ & Popflal-15 & $\begin{array}{l}\text { Análisis de expresión } \\
\text { (PCR semi-cuantitativa) }\end{array}$ & $\begin{array}{l}10 \text { isoformas presentan alta } \\
\text { expresión en madera de } \\
\text { tensión y nula expresión en } \\
\text { madera opuesta. }\end{array}$ & $\begin{array}{l}\text { Lafarguette } \\
\text { et al. } 2007\end{array}$ \\
\hline & E. grandis & $\begin{array}{l}\text { Egrflal y } \\
\text { Egrfla2 }\end{array}$ & $\begin{array}{l}\text { Análisis de expresión } \\
\text { (Northern blot) }\end{array}$ & $\begin{array}{l}\text { Mayor expresión en xilema } \\
\text { superior de ramas, respecto a } \\
\text { xilema inferior y vertical. }\end{array}$ & $\begin{array}{l}\text { Qiu et al. } \\
\quad 2008\end{array}$ \\
\hline & E. nitens & $\begin{array}{l}\text { Eniflal y } \\
\text { Enifla } 2\end{array}$ & $\begin{array}{l}\text { Análisis de expresión } \\
\text { (Northern blot) }\end{array}$ & $\begin{array}{l}\text { Mayor expresión en xilema } \\
\text { superior de ramas, respecto a } \\
\text { xilema inferior y vertical. }\end{array}$ & $\begin{array}{l}\text { MacMillan } \\
\text { et al. } 2010\end{array}$ \\
\hline & A. thaliana & $\begin{array}{l}\text { Atflal1 y } \\
\text { Atflal2 }\end{array}$ & $\begin{array}{c}\text { Transformación } \\
\text { genética (Líneas } \\
\text { mutantes) }\end{array}$ & Alteración en el MFA. & $\begin{array}{l}\text { MacMillan } \\
\text { et al. } 2010\end{array}$ \\
\hline
\end{tabular}




\section{CONCLUSIONES}

El crecimiento y desarrollo celular de los elementos anatómicos que componen el xilema son procesos complejos que están siendo modulados por una variedad de genes que codifican para enzimas y proteínas que estarán determinando las dimensiones y características específicas de cada uno de los elementos celulares que conforman el xilema. De acuerdo a las investigaciones aquí revisadas, cada uno de los genes está participando en una serie de etapas durante el desarrollo del xilema, incidiendo directamente sobre la morfología y anatomía celular, afectando las características biomecánicas de la madera. La actividad de los genes que codifican para EXP, PME y XTH tendrían un efecto específico sobre la pared celular primaria, promoviendo su ablandamiento, involucrándose en la expansión y elongación celular, donde algunos participan netamente en lo que se refiere al crecimiento intrusivo de algunos elementos celulares, otros en el crecimiento simplástico y algunos en ambos tipos de crecimiento. De acuerdo a lo reportado, es necesaria la acción inicial de un grupo de enzimas para que posteriormente otras puedan actuar, funcionando teóricamente como un proceso secuencial, donde además puede ser que algunos de los genes involucrados sean de efecto mayor, y otros de efecto menor, pero claves en el proceso.

Por otra parte, durante la etapa de deposición de la pared celular secundaria, el conocimiento existente respecto a los genes que regulan la orientación de las microfibrillas en la capa S2 ( $t u b$ y $f l a$ ) es escaso, pero al evaluar sus efectos sobre las características biomecánicas, éstos son claros; sin embargo, no existe evidencia experimental que indique el mecanismo mediante el cual estas proteínas están controlando la orientación de las microfibrillas de celulosa en la pared celular. Por lo tanto, para conocer y entender qué es lo que está ocurriendo durante la formación de la madera y cuáles son los genes involucrados en la determinación de sus propiedades, es necesario generar información y tener una visión integral que combine el efecto de un conjunto de genes, tanto los aquí reportados, como otros; para así poder generar estrategias que permitan implementar nuevas tecnologías de mejoramiento que en un futuro cercano permitan facilitar la selección clonal de las características de interés, teniendo impacto en los planes de mejoramiento tradicional de especies forestales, acortando los ciclos de mejoramiento y la identificación de genotipos útiles para fines específicos.

\section{AGRADECIMIENTOS}

Proyectos FONDECYT 1110828 e INNOVA-CHILE 05CTE04-01.

\section{REFERENCIAS}

Baskin, T.I. 2001. On the alignment of cellulose microfibrils by cortical microtubules: a review and a model. Protoplasma 215(1-4):150-171.

Bhandari, S.; Fujino, T.; Thammanagowda, S.; Zhang, D.; Xu, F.; Joshi, C.P. 2006. Xylemspecific and tensión stress-responsive coexpression of KORRIGAN endoglucanase and three secondary wall-associated cellulose synthase genes in aspen trees. Planta 224(4):828-837.

Bourquin, V.; Nishikubo, N.; Abe, H.; Brumer, H.; Denman, S.; Eklund, M.; Christiernin, M.; Teeri, T.T.; Sundberg, B.; Mellerowicz, E.J. 2002. Xyloglucan endotransglycosylases have a function during the formation of secondary cell walls of vascular tissues. Plant Cell 14(12):3073-3088.

Butterfield, B. 2006. The structure of wood: form and function. In: Primary Wood Processing, Walker J.C.F. (ed), Springer, Dordrecht, pp. 1-22.

Cosgrove, D.J. 2000. Loosening of plant cell walls by expansins. Nature 407(6802):321-326. 
Cosgrove, D.J. 2005. Growth of the plant cell wall. Nature Rev. Mol. Cell Biol. 6(11):850-861.

Darley, C.P.; Forrester, A.M.; McQueen-Mason, S.J. 2001. The molecular basis of plant cell wall expansion. Plant Mol. Biol. 47(1-2):179-195.

Déjardin, A.; Laurans, F.; Arnaud, D.; Breton, C.; Pilate, G.; Leple, J.C. 2010. Wood formation in Angiosperms. C. R. Biol. 333(4):325-334.

Ek, M.; Gellerstedt, G.; Henriksson, G. 2009. Pulp and paper Chemistry and Technology. vol. 1. Wood Chemistry and Wood Biotechnology. GmbH \& Co. KG, Berlin. 320 pp.

Fry, S.; Smith, R.; Renwick, K.; Martin, D.; Hodge, S.; Matthews, K. 1992. Xyloglucan endotransglycosylase, a new wall-loosening enzyme activity from plants. Biochem J. 282(3):821-828.

Gaspar, Y.; Johnson, K.L.; McKenna, J.A.; Bacic, A.; Schultz, C.J. 2001. The complex structures of arabinogalactan-proteins and the journey towards understanding function. Plant Mol. Biol. 47(12):161-176.

Goulao, L.F.; Vieira-Silva, S.; Jackson, P.A. 2011. Association of hemicellulose and pectin modifying gene expression with Eucalyptus globulus secondary growth. Plant Physiol. Biochem. 49(8):873-881.

Gray-Mitsumune, M.; Blomquist, K.; McQueen-Mason, S.; Teeri, T.T.; Sundberg, B.; Mellerowicz, E.J. 2008. Ectopic expression of a wood abundant expansin PttEXPA1 promotes cell expansion in primary and secondary tissues in aspen. Plant Biotechnol. J. 6(1):62-72.

Gray-Mitsumune, M.; Mellerowicz, E.J.; Abe, H.; Schrader, J.; Winzéll, A.; Sterky, F.; Blomqvist, K.; McQueen-Mason, S.; Teeri, T.T.; Sundberg, B. 2004. Expansins abundant in secondary xylem belong to subgroup A of the $\alpha$-expansin gene family. Plant Physiol. 135(3):1552-1564.

Gunning, B.S.; Steer, M.W. 1996. Plant Cell Biology: Structure and Function. Jones and Bartlett Publishers, Boston. 210 pp.

Hertzberg, M.; Aspeborg, H.; Schrader, J.; Andersson, A.; Erlandsson, R.; Blomqvist, K.; Bhalerao, R.; Uhlen, M.; Teeri, T.T.; Lundeberg, J.; Sundberg, B.; Nilsson, P.; Sandberg, G. 2001. A transcriptional roadmap to wood formation. Proc. Natl. Acad. Sci. USA. 98:

$14732-14737$.

Im, K.H; Cosgrove, D.J.; Jones, A.M. 2000. Subcellular localization of expansin mRNA in xylem cells. Plant Physiol. 123(2):463-470.

Johnson, K.L.; Jones, B.J.; Bacic, A.; Schultz, C.J. 2003. The Fasciclin-like arabinogalactan proteins of Arabidopsis. A multigene family of putative cell adhesión molecules. Plant Physiol. 133(4):1911-1925.

Karlsson, H. 2006. Fibre guide: fibre analysis and process applications in the pulp and paper industry. AB Lorentzen \& Wettre, Elanders Tofters, Sweden. 120 pp.

Knox, J.P.; Linstead, P.J.; King, J.; Cooper, C.; Roberts, K. 1990. Pectin esterification is spatially regulated both within cell walls and between developing tissues of root apices. Planta 181(4):512-521. 
Lafarguette, F.; Leplé, J.C.; Déjardin, A.; Laurans, F.; Costa, G.; Lesage-Descauses, M.C.; Pilate, G. 2004. Poplar genes encoding fasciclin-like arabinogalactan proteins are highly expressed in tension wood. New Phytol. 164(1):107-121.

Li, L.; Lu, S.; Chiang, V. 2006. A genomic and molecular view of wood formation. Crit Rev Plant Sci. 25(3):215-233.

MacMillan, C.P; Mansfield, S.D; Stachurski, Z.H; Evans, R.; Southerton, S.G. 2010. Fasciclinlike arabinogalactan proteins: specialization for stem biomechanics and cell wall architecture in Arabidopsis and Eucalyptus. Plant J. 62(4):689-703.

Mellerowicz, E.J.; Baucher, M.; Sundberg, B.; Boerjan, W. 2001. Unravelling cell wall formation in the woody dicot stem. Plant Mol. Biol. 47(1-2):239-274.

Mellerowicz, E.J.; Sunberg, B. 2008. Wood cell walls: biosynthesis, developmental dynamics and their implications for wood properties. Curr. Opin. Plant Biol. 11(3):293-300.

Nishikubo, N.; Takahashi, J.; Roos, A.A.; Derba-Maceluch, M.; Piens, K.; Brumer, H.; Teeri, T.T.; Stalbrand, H.; Mellerowicz, E.J. 2011. Xyloglucan endo-transglycosylase-mediated xyloglucan rearrangements in developing wood of hybrid Aspen. Plant Physiol. 155(1):399-413.

Oakley, R.V.; Wang, Y.S.; Ramakrishna, W.; Harding, S.A.; Tsai, C.J. 2007. Differential expansion and expression of a- and b-tubulin gene families in Populus. Plant Physiol. 145(3):961-973.

Paredez, A.R.; Somerville, C.R.; Ehrhardt, D.W. 2006. Visualization of cellulose synthase demonstrates functional association with microtubules. Science 312(5779):1491-1495.

Pelleoux, J.; Rustérucci, C.; Mellerowicz, E.J. 2007. New insights into pectin methylesterase structure and function. Trends Plant Sci. 12(6):267-277.

Qiu, D.; Wilson, I.W.; Gan, S.; Washusen, R.; Moran, G.F.; Southerton, S.G. 2008. Gene expression in Eucalyptus branch wood with marked variation in cellulose microfibril orientation and lacking G-layers. New Phytol. 179(1):94-103.

Rayle, D.L.; Cleland, R.E. 1992. The acid growth theory of Auxin-induced cell elongation is alive and well. Plant Physiol. 99(4):1271-1274.

Sampedro, J.; Cosgrove, D.J. 2005. The expansin superfamily. Genome Biol. 6(12):242.

Siedlecka, A.; Wiklund, S.; Péronne, M.A.; Micheli, F.; Leśniewska, J.; Sethson, I.; Edlund, U.; Richard, L.; Sundberg, B.; Mellerowicz, E.J. 2008. Pectin methyl esterase inhibits intrusive and symplastic cell growth in developing wood cells of Populus. Plant Physiol. 146(2):554-565.

Somerville, C. 2006. Cellulose synthesis in higher plants. Annu. Rev. Cell Dev. Biol. 22:53-78.

Spokevicius, A.V.; Southerton, S.G.; MacMillan, C.P.; Qiu, D.; Gan, S.; Tibbits, J.F.; Moran, G.F.; Bossinger, G. 2007. Beta-tubulin affects cellulose microfibril orientation in plant secondary fibre cell walls. Plant J. 51(4):717-726.

Sulová, Z.; Takácová, M.; Steele, N.M.; Fry, S.C.; Farkas, V. 1998. Xyloglucan endotransglycosylase: evidence for the existence of a relatively stable glycosyl-enzyme intermediate. Biochem. J. 220(3):14751480 . 
Taiz, L.; Zeiger, E. 2003. Plant physiology. 3rd ed. Sinauer Associates Inc. Sunderland, MA. 690pp.

Thomas, R.J. 1977. Wood: Structure and Chemical Composition. In Wood Technology: Chemical Aspects. ACS Syposium Series; American Chemical Society. Washington DC. USA. 23pp.

Vissenberg, K.; Martínez-Vilchez, I.M.; Verbelen J.P.; Miller, J.G.; Fry, S.C. 2000. In vivo colocalization of xyloglucan endotransglycosylase activity and its donor substrate in the elongation zone of Arabidopsis roots. Plant Cell. 12(7):1229-1238.

Washusen, R.; Evans, R.; Southerton, S. 2005. A study of Eucalyptus grandis and Eucalyptus globulus branch Wood microstructure. IAWA J. 26(2):203-210.

Xu, W.; Campbell, P.; Vargheese, A.K.; Braam, J. 1996. The Arabidopsis XET-related gene family: environmental and hormonal regulation of expression. Plant J. 9(6):879-889.

Zhong, R.; Burk, D.; Morrison, W.; Ye, Z. 2002. A kinesin-like protein is essential for oriented deposition of cellulose microfibrils and cell wall strength. Plant Cell 14(12):3101-3117.

\begin{tabular}{|c|c|c|}
\hline \multicolumn{3}{|l|}{ Abreviaturas } \\
\hline AGPs & $:$ & Proteínas arabinogalactano \\
\hline ATPasa & : & Adenosin-trifosfatasa \\
\hline CaMV & $:$ & Virus del mosaico de la coliflor \\
\hline CesA & $:$ & Celulosa sintasa \\
\hline EST & $:$ & Etiquetas de secuencias expresadas \\
\hline EXP (enzima)/exp (gen) & $:$ & Expansinas \\
\hline EXPA (enzima)/expa (gen) & $:$ & $\alpha$-expansinas \\
\hline EXPB (enzima)/expb (gen) & $:$ & $\beta$-expansinas \\
\hline FLA (proteína)/fla (gen) & $:$ & Fasciclin tipo arabinogalactanos \\
\hline HGA & $:$ & Homogalacturano \\
\hline MFA & $:$ & Ángulo microfibrilar \\
\hline PCR & $:$ & Reacción en cadena de la polimerasa \\
\hline PME (enzima)/pme (gen) & $:$ & Pectin metil esterasas \\
\hline qRT-PCR & $:$ & PCR en tiempo real \\
\hline TUA(proteína)/tub (gen) & $:$ & $\alpha$-tubulina \\
\hline TUB(proteína)/tub (gen) & $:$ & $\beta$-tubulina \\
\hline $\mathrm{XEH}$ & $:$ & Xiloglucano endohidrolasa \\
\hline XET & $:$ & Xiloglucano endotransglicolasa \\
\hline XTH (enzima)/xth (gen) & $:$ & $\begin{array}{l}\text { Xiloglucano } \\
\text { endotransglicosilasas/hidrolasas }\end{array}$ \\
\hline
\end{tabular}

